\title{
OS DESAFIOS ENTRE O ENSINO PRESENCIAL E O ENSINO A DISTÂNCIA: UMA QUESTÃO DE CULTURA DIGITAL E DE FORMAÇÃO DO EDUCADOR
}

\author{
Francisco Ramos de Farias | frfarias@uol.com.br \\ Doutor em Psicologia pela Fundação Getulio Vargas - FGV, Professor Adjunto da Universidade Federal do Estado do Rio de Janeiro - \\ UNIRIO.
}

Mário José Dias | dias.mj@globo.com

Doutorando em Memória Social pela Universidade Federal do Estado do Rio de Janeiro - UNIRIO, Coordenador do Curso de Filosofia do Centro Universitário Salesiano de São Paulo - Unidade de Lorena.

\section{Resumo}

O presente artigo tem como finalidade refletir sobre a cultura digital como um elemento significativo na implementação de cursos a distância $e$ os desafios frente à estrutura de uma educação formal. O mundo digital é uma realidade, e por isso mesmo impulsiona o surgimento de um repensar sobre a cultura $e$, consequentemente, sobre a sociedade. Ele está aí presente no cotidiano das relações. Da simples compra que se faz à consulta de um saldo bancário, a tecnologia diz "presente". E na educação, em que carteira escolar pode a tecnologia se sentar? O artigo reafirma a importância do professor como animador e estimulador da aprendizagem, recurso importante à implantação de uma cultura digital.

\section{Palavras-chave}

Cultura. EAD. Virtualidade. Escola. 
CHALLENGES BETWEEN CLASSROOM AND DISTANCE LEARNING: A MATTER OF DIGITAL CULTURE AND EDUCATOR TRAINING

\section{Abstract}

The purpose of this article is to reflect about digital culture as a significant element in the implementation of distance learning and its challenges vis-à-vis the formal education structure. The digital world is a reality and for this very reason generates a new outlook about our culture and, consequently, about our society. The digital world is omnipresent in our daily routines, from a single buying transaction to consulting one's bank balance. And in the educational environment, at which school desk can technology sit? This article underscores the importance of the teacher as an entertainer and as a facilitator of learning - an important resource for implementing digital culture.

\section{Keywords}

Culture. Distance learning. Virtuality. School.

\section{LOS DESAFÍOS ENTRE LA ENSEÑANZA} PRESENCIAL Y LA ENSEÑANZA VIRTUAL: UNA CUESTIÓN DE CULTURA DIGITAL Y DE FORMACIÓN DEL EDUCADOR

\section{Resumen}

El presente artículo plantea una reflexión sobre la cultura digital como elemento significativo en la implementación de cursos a distancia y los desafíos frente a la estructura de la educación formal. El mundo digital es una realidad que impulsa el surgimiento de nuevas reflexiones sobre la cultura y, por consiguiente, sobre la sociedad. Él está ahí, presente, en las relaciones interpersonales diarias. Desde una simple compra hasta una consulta bancaria, la tecnología se hace presente. En la educación ¿en qué pupitre podría sentarse la tecnología? Este estudio reafirma la importancia del profesor como animador y estimulador del aprendizaje, recurso importante en la implementación de una cultura digital.

\section{Palabras clave}

Cultura. EAD. Virtualidad. Escuela.

\section{Introdução}

O que esperar de um curso a distância? Pode efetivamente este curso qualificar pessoas críticas e transformadoras? Que conceito de pessoa está se criando a partir dos cursos em EAD? Como educar e criar uma comunidade virtual disposta a enfrentar a realidade de uma sociedade?

Essas questões e outras poderiam surgir ao se pensar na proliferação dos cursos na modalidade EAD. E são naturais a preocupação $e$ as dúvidas que decorrem desse novo paradigma e, ao mesmo tempo, do velho dilema entre o mundo real e o mundo virtual.

O mundo digital é uma realidade e por isso mesmo impulsiona o surgimento de um repensar sobre a cultura e, consequentemente, sobre a sociedade. Ele está aí presente no cotidiano das relações. Da simples compra que se faz à consulta de um saldo bancário, a tecnologia diz "presente". E na educação, em que carteira escolar pode a tecnologia se sentar?

Este é o problema sobre o qual se quer refletir no presente artigo: a natureza do pensar a tecnologia enquanto ferramenta para um novo jeito de aprender no mundo moderno. Os desafios são enormes, principalmente no campo de uma cultura em que se fundamenta e se estrutura a educação dita formal.

Outra questão decorre dessa realidade e parece ainda não estar resolvida: a exclusão digital e a cultura digital. Este artigo suscita duas hipóteses:

a) Pode-se ter acesso ao mundo informatizado, enquanto equipamento, buscar o entretenimento virtual como possibilidade de vencer desafios, mas ter acesso a tudo isso não significa efetivamente possuir uma cultura digital.

b) A maioria de crianças e jovens que utiliza a tecnologia impulsiona a sociedade a repensar suas práticas educativas e força o debate e a reflexão sobre a forma mais eficaz em que se processam o ensino e a aprendizagem.

Entre as muitas publicações que versam sobre o assunto, assumiu-se com base teórica desse artigo a discussão de Hugo Assman (2005), presente na obra Redes digitais e metamorfose do aprender, em 
que o autor busca com outros autores definir alguns pressupostos sobre a dita sociedade do conhecimento e da informação.

Autores como Perry Levy e Pedro Demo não poderiam deixar de ser consultados como marca de um processo de encontro entre a "Inteligência artificial" (2000) e o "Charme da exclusão social" (1998), estudos interessantes que se completam à medida em que compreendem que a grande questão está centrada na busca de um novo paradigma.

Para melhor compreender os objetivos a que se propõe o presente artigo, buscou-se como fonte as propostas apresentadas por Jacques Delors (1996), em Educação um tesouro a descobrir. Neste documento, os chamados "Códigos da Modernidade para o século XXI" constituem uma referência primordial para a busca de respostas:

1. domínio da leitura e da escrita;

2. capacidade de fazer cálculos e de resolver problemas;

3. capacidade de compreender e atuar em seu entorno social;

4. capacidade de analisar, sintetizar e interpretar dados, fatos e situações;

5. capacidade de receber criticamente os meios de comunicação;

6. capacidade para localizar, acessar e usar melhor a informação acumulada;

7. capacidade de planejar, trabalhar e decidir em grupo.

A modernidade clama um caminho novo. O perfil da pessoa está focado em uma educação que possibilite um:

1. aprender a ser que leve a desenvolver uma competência pessoal;

2. aprender a conviver que desenvolva a competência social;

3. aprender a fazer que permita o desenvolvimento de uma competência produtiva;

4. aprender a aprender que desperte nela a competência cognitiva.
Os desafios e os encontros com o mundo digital enquanto processos de ensino-aprendizagem se tornam um desafio, pois ainda há uma enorme gama de fatores que podem e devem contribuir para uma reflexão mais aprofundada sobre o novo sentido da educação.

\section{Em busca de uma definição para a EAD}

Dentre as várias definições disponíveis, optou-se por escolher a definição clássica apresentada por Aretio Garcia, por acreditar estar bem próxima do espírito da LDB em vigor no Brasil.

O Ensino a Distância é um sistema tecnológico de comunicação bidirecional, que pode ser massivo e que substitui a interação pessoal, na sala de aula, de professor e aluno, como meio preferencial de ensino, pela ação sistemática e conjunta de diversos recursos didáticos e pelo apoio de uma organização e tutoria que propiciam a aprendizagem independente e flexível dos alunos (GARCIA, 1994, p. 45, grifo nosso).

$\mathrm{O}$ autor apresenta como síntese que a EAD se pauta pela "comunicação bidirecional", ou seja, ela pode ser entendida como o princípio básico do "aprender a aprender", e que, portanto, pressupõe a autonomia da aprendizagem como sua grande intencionalidade. Por se caracterizar como um sistema tecnológico, há de se perceber que as ferramentas apresentadas devem propiciar ao aluno recursos didáticos e de apoio necessários ao seu desenvolvimento.

Há de se questionar nessa concepção a "substituição da interação pessoal", uma vez que a mudança de paradigma se instaura como necessária na busca de um novo sentido de interação. A EAD substitui, na verdade, o conceito tradicional de interação real pelo da interação virtual.

A amplitude de tal concepção está nos elementos fundantes da EAD: autonomia, flexibilidade, aproximação das distâncias, aprendizagem individual e coletiva.

Outro elemento importante que a definição apresenta está justamente no caráter do "pode ser massivo", tentando dar à EAD o caráter não excludente nem solitário, uma vez que a tecnologia é posta como possibilidade de acessibilidade a todos e que o aprender não se dá de forma isolada, uma vez que a sala virtual comporta um conjunto "classe". Uma sala convencional, presencial, é substituída por uma 
sala virtual, com iguais possibilidades de interação de ideias, normas etc.

O conceito também pressupõe "organização $e$ tutoria" como elemento fundamental para que a aprendizagem ocorra. Aqui encontramos a natureza dos conceitos de presença ativa do professor/tutor. Parece responder a uma questão angustiante nos blocos resistentes à EAD, que apontam "o fim do professor". Ao contrário, a EAD não exclui a presença do professor, discute seu novo papel, sua nova identidade. Esse conceito deixa claro que, para um novo tempo, de tecnologias avançadas, um novo professor precisa surgir.

Uma observação necessária está na responsabilidade e na intencionalidade dos programas de EAD. Existe aqui uma contribuição bastante interessante $e$ de importância fundamental: a cumplicidade da EAD com o indivíduo e a formação social.

Nesse contexto, temos que levar em conta que não podemos transformar a EAD em um instrumento simplesmente mercadológico, corre-se o risco de banalizar e perder o sentido único da $\mathrm{EAD}$, que é a formação do indivíduo. Daí, é importante que haja sempre uma atenção para os cursos que são propostos e sua validade na sociedade.

A presença do professor, o seu novo papel e sua importância sintetizam a adequação da tecnologia e do humano, aproximam o ser humano da máquina.

Algumas das resistências que ainda se fazem presentes, estão nessa "aproximação do ser humano da máquina", uma vez que este processo de ensino se realiza predominantemente através da utilização de "tecnologias capazes de superar a distância física na comunicação entre os participantes desse processo" (PIMENTEL, 2009). Outro elemento, que por mais contraditório que possa parecer se faz presente na própria LDB (1996), quando esta anuncia ser uma modalidade "uma forma de ensino que possibilita a auto-aprendizagem (...) apresentados em diferentes suportes de informação".

Observando essas duas dimensões, "superação da distância física" e "auto-aprendizagem", pode-se avançar para a discussão entre aprendizagem, cultura e conhecimento.

A aprendizagem, discurso entre a teoria e a prática, se funde com a aquisição do conhecimento que se processa através da informação. Nesse sentido, é pertinente afirmar que a informação, disponível a todos, não está diretamente ligada à aquisição do conhecimento. Nem toda informação recebida significa, necessariamente, conhecimento adquirido.

Nesse sentido, "autonomia intelectual do aluno e a sua possibilidade de escolher espaços e tempos para realizar as atividades pedagógicas... como modalidade de educação, deve ser regida pela intencionalidade..." (GIUSTA, 2003, p. 47).

Essa intencionalidade presente na ação do sujeito sobre o objeto é que constitui efetivamente o conhecimento. A informação é a passagem necessária para que o indivíduo possa realizar suas escolhas e delas se apropriar de acordo com a sua visão de mundo.

Esse ato de aprender com suas escolhas é que torna possível a dimensão da EAD que quer ser uma decisão autônoma do indivíduo. Essa escolha entre o ensino presencial e o ensino a distância pode se configurar também como uma possibilidade de tornar real o sonho da democratização do ensino e, quem sabe, de uma real inclusão social.

Pode-se, a partir disso, configurar uma espécie de "pano de fundo" para a reflexão sobre a natureza da cultura.

\section{A cultura entre o real e o digital}

Para analisar essa questão, recorre-se ao sociólogo e filósofo alemão Norberto Elias:

À margem de um largo rio, ou talvez na encosta íngreme de uma montanha elevada, encontra-se uma fileira de estátuas. Elas não conseguem movimentar seus membros. Mas têm olhos e podem enxergar. Talvez ouvidos, também, capazes de ouvir. E sabem pensar. São dotadas de "entendimento". Podemos presumir que não vejam umas às outras, embora saibam perfeitamente que existem outras. Cada uma está isolada. Cada estátua em isolamento percebe que há algo acontecendo do outro lado do rio ou do vale. Cada uma tem idéias do que está acontecendo e medita sobre até que ponto essas idéias correspondem ao que está sucedendo. Algumas acham que essas idéias simplesmente espelham as ocorrências do lado oposto. Outras pensam que uma grande contribuição vem de seu próprio entendimento; no final, é impossível saber o que está acontecendo por lá. Cada estátua forma sua própria opinião. Tudo o que ela sabe provém de sua própria experiência. 
Ela sempre foi tal como é agora. Não se modifica. Enxerga. Observa. Há algo acontecendo do outro lado. Ela pensa nisso. Mas continua em aberto a questão de se o que ela pensa corresponde ao que lá está sucedendo. Ela não tem meios de se convencer. É imóvel. E está só. O abismo é profundo demais. O golfo é intransponível (1994, p. 89, grifo nosso).

Essa parábola, intitulada pelo autor "Estátuas Pensantes", reflete bem a análise que se quer fazer sobre a questão da cultura. "Elas não conseguem movimentar seus membros. Mas têm olhos e podem enxergar. Talvez ouvidos, também, capazes de ouvir. E sabem pensar. São dotadas de "entendimento". A cultura é, nesse sentido, um conjunto preestabelecido de normas e padrões que moldam os indivíduos em sociedade.

Indivíduos "dotados de entendimentos, "capazes de ouvir, enxergar", no entanto moldados ao seu mundo, incapazes de se mover, para ver o outro lado do "mundo". A visão é um deslumbramento das possibilidades, mas o real se configura, muitas vezes, na impossibilidade das barreiras das dificuldades.

Segundo Tylor,

cultura ou civilização, tomada em seu amplo sentido etnográfico, é todo complexo que inclui conhecimentos, crenças, arte, moral, leis, costumes, e quaisquer outras capacidades e hábitos adquiridos pelo homem como membro da sociedade. A condição da cultura entre as diversas sociedades da humanidade, na medida em que é susceptível de ser investigada nos princípios gerais, é um assunto apto para o estudo das leis do pensamento humano e de ação (1903, p. 1, tradução nossa).

Pode-se acreditar que a pessoa passa, pois, a criar seus próprios mecanismos de defesa, que dificulta a entrada do novo, da "ponte" que dará acesso ao outro lado da margem, prefere ficar a pensar sobre as possibilidades como um campo utópico, de acesso somente aos "privilegiados", aos que detêm o poder de controlar e manipular as mudanças. Acredita-se ser este o campo onde se situa, mais ferozmente, a chamada "exclusão social".

Nesse sentido, Pedro Demo (1998), em seu livro Charme da exclusão social, afirma ser este uma característica do modelo econômico brasileiro, favorecido pela concentração de capital, resultando num aumento substancial do número de pobres e miseráveis do país. Àqueles não inseridos no sistema, restava somente vender a sua força de trabalho sem, contudo, se tornarem aptos aos privilégios existentes.

Se no plano econômico pode-se definir com mais eficácia a questão da exclusão social, no campo educacional acredita-se não estar longe de tais conclusões semelhantes. As bases de um sustentam o paradigma do outro.

Nesse sentido, tanto a parábola de Elias quanto a contribuição de Demo reportam-se à questão da aprendizagem e da cultura da exclusão:

Primeiro, podemos lembrar que aprendizagem exige a presença de um sujeito autônomo e que ela mesma é processo de formação da autonomia do sujeito. Segundo podemos aduzir que, sendo seres interpretativos, sempre interferimos na realidade, para o bem ou para o mal, o que, aliás, também poderia ser fundamento para esperar atitude ética. Terceiro, o instrucionismo indica interferência reprodutiva, abuso de poder, preformação da consciência alheia. Não se trata apenas de aprender pela cópia (obstruir a atividade reconstrutiva), mas, sobretudo de agredir a autonomia do sujeito ou mesmo de a impedir (DEMO, 2009).

As práticas educacionais, em sua maioria, estão pautadas nesse discurso do instrucionismo, muitas vezes com a "cara" de moderno, que reforça o paradigma excludente e constitui uma forte resistência ao novo.

A cultura dominante passa então a determinar os processos de continuidade e de mudança. Até onde se pode chegar, quem pode chegar, e como pode chegar.

\section{O conhecimento e a realidade: ponto de encontro com a cultura}

O conhecimento é a adequação do objeto ao sujeito. Esse princípio que nasce da filosofia, parte do princípio que todo o ato de conhecer é sempre uma transposição daquilo que aprendemos com a capacidade que temos para utilizá-lo na realidade, transformando e nos adaptando à mudança.

O conhecimento como ato dinâmico e dialético pressupõe e necessita da realidade. "Nada aprendi que não tivesse que sair", afirma o filósofo francês Michel Serres (1993). Esse ato de sair pressupõe o tornar-se disponível para o aprender. Nesse sentido, a pessoa necessita tornar-se disponível.

Atuar sobre a realidade é aceitar a cumplicidade que nasce do ato de aprender. Não se pode confundir o 
atuar com condicionamento social, com adaptação ao meio, mas transformar. "A acomodação aparece, pois, como o termo complementar da relação sujeito versus objeto pondo em evidência o valor das resistências do objeto imposto ao sujeito" (GIUSTA, 2003, p. 55).

Nesse sentido, Piaget (1976) reforça a necessidades constante do sujeito ao conhecer a realidade intervir e transformar o meio. $\mathrm{O}$ conhecimento adquire aí uma função primordial de unidade e sintonia com o sujeito e a realidade. Sendo assim, "o sujeito da aprendizagem, como sujeito do conhecimento, requer um meio cada vez mais alargado que lhe possibilite informações que possam ser, por ele, ressignificadas"(GIUSTA, 2003, p. 56).

Para completar esse aspecto da teoria piagetiana, Vigotski (1998) acrescenta, se é que se pode assim entender, o elemento linguagem como condição de explicitar o conhecimento e atribuir significados novos. Nesse sentido, o ato de conhecer passa pela descoberta do outro que torna visível a nossa existência.

A realidade, complexa e simbólica, apresenta-se ao sujeito (e o sujeito a ela) cujo pensamento é engendrado pelas necessidades, desejos, interesses e emoções, e o entendimento da linguagem do outro só é possível pela compreensão do seu pensamento $e$, mais ainda, da base afetivo-volitiva deste pensamento (VIGOTSKI, 1998).

Acrescenta-se a essa reflexão a contribuição de Morin (2001), que, ao falar do princípio da intercomunicação com o semelhante, atribui ao processo dialético a tarefa de buscar um caminho entre a realidade externa e o sujeito. Na relação pedagógica há, sem dúvida, uma complexidade entre a proximidade $e$ o distanciamento, entre a inclusão e a exclusão. A esse respeito, Giusta (2003, p. 63) afirma que toda a complexidade do ser sujeito traz como desdobramento para a relação ensino/aprendizagem a impossibilidade de decidir pelo e para o aluno... o ato de aprender não se restringe ao registro de informações fornecidas pelo meio.

Ao buscar um elo entre o aprender, a cultura, o virtual e a exclusão social, torna-se necessário aprofundar a questão da linguagem. Entre os vários estudos sobre a linguagem, optou-se por trabalhar com o conceito de Bakhtin, uma vez que para ele não há produção cultural fora da linguagem.

\section{A linguagem e o sentido do aprender em Bakhtin}

Para Bakhtin (2006), o homem constrói sua existência dentro das condições socioeconômicas objetivas de uma sociedade. Somente como membro de um grupo social, de uma classe social é que o indivíduo ascende a uma realidade histórica e a uma produtividade cultural.

Ao analisar os estudos de Bakhtin, é possível perceber que sua proposta perpassa o pedagógico à medida que o mesmo encontra como caminho do conhecimento a linguagem. Sua vasta obra tem na linguagem sua centralidade, analisando-a do ponto de vista do "subjetivismo idealista" e do "objetivismo abstrato".

Para o subjetivismo idealista, o fenômeno linguístico é ato significativo de criação individual: "a língua é atividade criativa ininterrupta; as leis da lingüística são leis da psicologia individual $e$ a criação linguística é análoga à artística" (KRAMER, 1994, p. 72).

Para o objetivismo abstrato, nem a fala nem a linguagem são objetos da linguística. Separando a língua (social) da fala (individual), toma-se a primeira como objeto e delega-se à linguística a tarefa de estudar e descrever as formas normativas.

Segundo Bakhtin (2006, p. 96) para o locutor importa o signo sempre flexível e variável, enquanto para o receptor o essencial não é reconhecer a forma usada, mas compreendê-la num contexto preciso, captando sua significação numa enunciação particular, percebendo seu caráter de novidade.

Nas palavras do autor:

assim, na prática viva da língua, a consciência lingüística do locutor e do receptor nada tem a ver com um sistema abstrato de formas normativas, mas apenas com a linguagem no sentido de conjunto dos contextos possíveis de uso de cada forma particular.

Nesse sentido, pode-se afirmar que o encontro da proposta pedagógica está em reconhecer os signos como forma de integração do indivíduo com a sociedade. É a sua própria inserção na comunidade social.

Em tempos de encontro e desencontro do virtual com o real, a sociedade busca um novo código de inserção social que aproxime os indivíduos dos diversos grupos sociais. 
Não há nada na composição do sentido que possa colocarse acima da evolução, que seja independente do alargamento dialético do horizonte social. A sociedade em transformação alarga-se para integrar o ser em transformação. Nada pode permanecer estável nesse processo. É por isso que a significação, elemento abstrato igual a si mesmo, é absorvida pelo tema, e dilacerada por suas contradições vivas, para retornar enfim sob a forma de uma nova significação com uma estabilidade e uma identidade igualmente provisórias (BAKHTIN, 2006, p. 139, grifo nosso).

$\mathrm{Na}$ medida em que os enunciados concretos se conectam com o contexto extraverbal da vida, separados desse contexto eles perdem a sua significação. Desse modo, para compreender o enunciado, é preciso compreender o dito e o presumido, o dito $e$ o não dito.

Tudo, portanto, se passa como se o mundo ao redor do falante estivesse cheio de forças vivas, o que significa que o indivíduo se adapta ao seu meio. A vida o penetra $e$ influencia de dentro, e a energia de uma situação da vida é bombardeada para o discurso verbal. "A seleção do conteúdo e a seleção da forma constituem um e o mesmo ato estabelecendo a posição básica do criador, e nesse ato uma e a mesma avaliação social encontra a expressão" (VOLOSHINOV, 2009).

Cabe, portanto, uma consideração ao projeto que une o social ao digital. A nova linguagem digital apresenta-se, pois, como um caminho necessário à aproximação do indivíduo do mundo que o cerca. Este mundo possui novos códigos, novas formas $e$ novas linguagens.

\section{A cultura e o aprender em Pierre Lévy}

Sempre que surge algo novo na sociedade há uma tendência natural das pessoas em observar o cenário; como ele se comporta, quais os desafios, as dificuldades e qual a posição mais prudente que se deve tomar. Foi neste contexto que Pierre Lévy se encontrava em 1999, quando apresentou uma nova versão para o termo "ciberespaço", surgido em 1984 pelo escritor William Gibson.

Para Lévy, ciberespaço significava um novo meio de comunicação, cuja finalidade era interligar o mundo da informação. Com isso era possível imaginar uma tecnologia digital capaz de apresentar uma nova for- ma de escrever e de ler o mundo. Por isso mesmo, alertava:

Antes de condenar os videogames, os humanistas, os pedagogos, os criadores, os autores deveriam valer-se desta nova escritura e produzir com ela obras dignas desse nome, inventar novas formas de saber e exploração que lhes correspondam, dar-lhes seus títulos de nobreza. Nada seria pior do que uma situação em que as pessoas de cultura se crispassem sobre o território do texto alfabético, enquanto a linguagem do futuro seria deixada aos técnicos e comerciantes. A barbárie nasceu quase sempre da separação. Existe um conhecimento por simulação, muito diferente dos estilos teóricos e hermenêuticos que se apoiavam sobre a escritura estática. Esses critérios principais não são sem dúvida mais aqueles da verdade crítica, universal e objetiva, mas antes aqueles da potência de bifurcação e de variação, da capacidade de mutação, de operatividade, de pertinência local, contextual (LÉVY, 2009b, grifo nosso).

A questão que se aborda aqui é tentar encontrar uma resposta à questão "O que seria o espaço cibernético?" Como pode este espaço modificar as estruturas de pensamento da modernidade? Pode o ciberespaço estabelecer uma "ponte" de ruptura com as "Estátuas Pensantes"? Segundo Pierre Lévy:

O espaço cibernético é um terreno onde está funcionando a humanidade, hoje. É um novo espaço de interação humana que já tem uma importância enorme sobretudo no plano econômico e científico e, certamente, essa importância vai ampliar-se e vai estender-se a vários outros campos, como por exemplo na Pedagogia, Estética, Arte e Política (apud PELLANDA, 2000, p. 14)

A sociedade, por viver este momento de transição, está se transformando numa esfera informatizada. Ao se perceber informatizada os padrões culturais começam a entrar em uma espécie de gestação. É esta uma contribuição bastante interessante que nos reporta a Lévy. Segundo o autor é neste espaço cibernético que encontramos "uma ferramenta de comunicação muito diferente da mídia clássica, porque é nesse espaço que todas as mensagens se tornam interativas, ganham uma plasticidade e têm uma possibilidade de metamorfose imediata" (2000, p. 14).

Esta metamorfose, que para o autor é a possibilidade de acessar, criar e estabelecer redes, possibilita um caminho importante para renovar a cultura.

Nós devemos, cada um a nosso modo, fazer com que o maior número de pessoas possível possam ter acesso a esse novo re- 
curso fundamental da cultura que é a comunicação mundial interativa. Aqueles que podem ter acesso sabem até que ponto isso é um recurso para o desenvolvimento pessoal, para estreitar laços sociais, para aprender coisas, para aumentar seu grau de liberdade, pois temos muito mais liberdade de expressão do que podíamos ter na época em que havia somente os jornais, o rádio, a televisão etc. (LÉVY, 2009b).

Para o autor este tempo em que vivemos é também um momento de revisão de "potencialização da sensibilidade, da percepção, do pensamento, da imaginação, e isso tudo graças a essas novas formas de cooperação e coordenação em tempo real". Aqui, a contribuição é bastante pertinente ao tema que se está abordando: a busca de um novo pensar que rompa com a dependência e estimule o aprendizado e a aquisição de saberes. Ao se estabelecer a cultura da rede, busca-se evitar o isolamento e a separação.

O espaço cibernético aqui é entendido como esse espaço virtual onde a comunidade conhece a si mesma e conhece seu próprio mundo, porque são duas faces da mesma coisa. Não se trata mais de uma enciclopédia, mas de uma espécie de plasmopédia, isto é, um espaço de saber vivo e dinâmico (LEVY, 2009c)

Na tipologia proposta por Levy - Um e Todo/ Um e Um/Todos e Todos - está presente a leitura importante que se faz do papel da comunicação e seus atributos formadores da cultura.

Uma cultura que quer ser plugada no mundo necessita romper as barreiras do individualismo e do ostracismo. A emergência desta inteligência coletiva - Todos e Todos - que, segundo o autor, está se tornando cada vez mais evidente, obriga cada vez mais pensar que "as informações vão se digladiando, $e$ cada um fica perdido nessa massa de informações.

Com as redes, podemos pensar em equipamentos de tecnologia que possam permitir que cada um se beneficie dessa inteligência" (LEVY apud PELLANDA,2000, p. 16)

\section{Finalmente, entre a EAD e a cultura digital}

A intenção até agora era fundamentar os elementos que configuram o saber, o aprender e suas relações com a cultura. O objetivo era situar o contexto em que se insere o Ensino a Distância e a sua contribuição na formação de um novo paradigma social.
Para Assman (2005), a expressão "sociedade da informação" deve ser entendida como abreviação de um aspecto da sociedade: o da presença cada vez mais acentuada das novas tecnologias da informação e da comunicação.

É exatamente a partir dessa característica tecnológica que aparece um novo sentido para o mundo, e, portanto, o surgimento de um novo ser humano.

Para esse novo modelo de sociedade, novo modelo de ser humano, há de se pensar o sentido da aprendizagem, que, como um processo, provocada por estímulos diversos e mediada por emoções tende a realizar uma mudança ou, simplesmente, conservar o comportamento humano.

Vários estudos sobre aprendizagem têm se configurado como uma ferramenta necessária para este repensar social. Peter Senge (2004, p. 38) afirma que o ser humano vem ao mundo motivado a aprender, a explorar e a experimentar.

(...) No fundo, somos todos aprendizes. Não é preciso ensinar uma criança a aprender. Elas são intrinsecamente curiosas, excelentes aprendizes, que aprendem a andar, falar e viver por conta própria. (...) Aprender não só faz parte da natureza humana (...) - nós adoramos aprender.

Tanto Senge quanto outros autores, apresentam como contribuição para os estudos sobre aprendizagem a dimensão da:

a. "aprendizagem operacional" que consiste na pura aquisição e no desenvolvimento de habilidades físicas para produzir as ações (know-how).

b. "aprendizagem conceitual" que consiste na aquisição e no desenvolvimento da capacidade de articulação com os conhecimentos conceituais sobre determinadas experiências.

Estabelece-se aqui o ponto de encontro entre os estudos apresentados tanto por Bakthin como por Pierre Levy e por Norberto Elias:

(...) a partir do desenvolvimento de novas habilidades e aptidões, altera-se a compreensão dos indivíduos sobre a realidade. Novos conhecimentos e sensibilidades, quando incorporados, modificam os modelos mentais das pessoas, compostos por idéias profundamente arraigadas, generalizações ou mesmo imagens que influenciam nosso modo de encarar o mundo e nossas atitudes (SENGE, 2004, p. 47). 
É nesse cenário de mudança que compreendemos a EAD e seu impacto na construção de um novo modelo educacional. A EAD é um conceito novo de solução para questões pedagógicas intrigantes, como o trabalho cooperativo, a autonomia e a responsabilidade.
A autonomia e a responsabilidade caminham juntas em um ambiente EAD. A informação disponibilizada a todos pode se concretizar em um conhecimento individual. Ao realizar tal passagem (informação para conhecimento), acredita-se que haverá uma interferência real na sociedade.

\section{Notas}

${ }^{1}$ Minuta do Regulamento, artigo 80 da Lei 9.394, de 20 de dezembro de 1996, que depois foi regulamentado pelo Decreto $\mathrm{n}^{\circ} 5.622$, de 19 de dezembro de 2005.

${ }^{2}$ Edward Tylor (1832-1917), antropologo norte-americano a quem se atribuiu o conceito de cultura. Conforme o pensamento desse autor, o homem sobreviveu ao tempo e às suas limitações orgânicas graças à cultura.

${ }^{3}$ Mikhail Mikhalovich Bakhtin (1895-1975). Nascido em Moscou, é considerado um dos teóricos da literatura e um filósofo da linguagem.

${ }^{4}$ Wiliam Gibson, escritor americano nascido em 1948 que ficou conhecido a partir de um romance de ficção científica, Neuromancer, publicado em 1984, onde, primeira vez, surge o termo "ciberpunk". 


\section{Referências bibliográficas}

ASSMAN, Hugo. Redes Digitais e metamorfose do Aprender. Petrópolis: Vozes, 2005.

BAKHTIN, Mikhail. Marxismo e filosofia da linguagem. Trad. JAKOBSON, Roman. 12 ed. São Paulo: Hucitec, 2006.

DELORS, Jacques. Educação, um tesouro a descobrir. Lisboa: ASA/UNESCO,1996

DEMO, Pedro. Charme da exclusão social. Campinas, São Paulo: Editora Autores Associados, 1998.

ELIAS, Norberto. A sociedade dos indivíduos. Tradução, Vera Ribeiro; revisão técnica e notas, Renato Janine Ribeiro. Rio de Janeiro: Zahar,1994.

GARCIA ARETIO, Lorenzo. Educacion a la distancia hoy. Madri: UNED, 1994.

GIUSTA, Agnela da Silva. Educação a distância: uma articulação entre a teoria e a prática. Belo Horizonte: PUC, 2003.

KRAMER, Sonia. Por entre as pedras: arma e sonho na escola. São Paulo: Ática, 1994.

LEVY, Pierre. A emergência do Cyberspace e as mutações culturais. In: PELLANDA, Eduardo Campos (org.). Ciberespaço: um hipertexto com Pierre Levy. Porto Alegre: Artes e Ofícios, 2000.

. Inteligencia colectiva: por una antropología del ciberespacio. Disponível em http://inteligenciacolectiva. bvsalud.org. Acessado em 06/06/2009a.

Tecnologias intelectuais e modos de conhecer: nós somos o texto. Disponível em: www.caosmose. net/candido/unisinos/textos/modos.doc. Acessado em 06/06/2009b.
A inteligência coletiva: nova fonte de potência Disponível em: www.sescsp.org.br/sesc/hotsites/pierre levy/Conferencia.doc. Acessado em 06/06/2009c.

MORIN, Edgar. Os sete saberes necessários à educação do futuro. 3a. ed. São Paulo: Cortez, 2001.

PELLANDA, Eduardo Campos (org.). Ciberespaço: um hipertexto com Pierre Levy. Porto Alegre: Artes e Ofícios, 2000.

PIAGET, Jean. A equilibração das estruturas cognitivas: problema central do desenvolvimento. Rio de Janeiro: Zahar, 1976.

PIMENTEL, Mariano Gomes; ANDRADE, Leila Cristina Vasconcelos de. Educação a distância: mecanismos para classificação e análise. Disponível em: http://www.inf.ufes.br/ sbie2001/figuras/artigos/ a192/a192.htm. Acessado em 07/06/2009.

SENGE, Peter. A quinta disciplina. São Paulo: Best Seller, 2004.

SERRES, Michel. Filosofia mestiça. Rio de Janeiro: Nova Fronteira, 1993.

TYLOR, Edward. Primitive culture: researches into the development of mythology, philosophy, religion, language, art, and custom. 4 ed. London: John Murray, Albemarle Stree, 1903.

VIGOTSKI, L. S. Pensamento e linguagem. São Paulo: Martins Fontes, 1998.

VOLOSHINOV, V. N. Discourse in life and discourse in art (concerning sociological poetics). In:

Freudianism: a marxist critique. New York Academic Press. Trad. Cristóvão Tezza - para uso didático. Disponível em http://www.linguagensdesenhadas. com/imagens/03 - textos/autores/Bakhtin_Discurso_ na_vida.pdf. Acessado em 07/06/2009. 